\title{
PRAKTIK PUBLIC RELATIONS DAN CORPORATE SOCIAL RESPONSIBILITY DALAM PERUBAHAN SOSIAL GLOBAL
}

\author{
Rina Juwita \\ Dosen Ilmu Komunikasi FISIP Universitas Mulawarman \\ Rinajuwita1704@gmail.com
}

\begin{abstract}
ABSTRAK
This paper tries to analyze the trends and patters working in public relations industry in term of Corporate Social Responsibility (CSR). Recent literatures from the PR scholars state that this field requires a broader approach in term of desaigning and implementing CSR rather than just being a small part of management communication function. However, as Clark proposed (2000), these activities should be integrated into the management function and become an important part of management component of the modern public relations. It is true since there are more positive opportunities in the implementation of social responsibility if it is integrated into the PR program if the approaches being used allows the establishment of a stronger relationship between organisation, stakeholders, and the public itself.
\end{abstract}

Kata Kunci: Public Relations, CSR, Social Exchange

\section{PENDAHULUAN}

Gagasan mengenai perusahaan yang harus bertanggung jawab secara sosial dimulai pada tahun 1960an, sebuah masa ketika banyak perusahaan bisnis di dunia mulai meluas secara internasional dan berkembang secara cepat dalam skala ukuran dan kekuasaan (Lantos, 2001).Sejak saat itu, permasalahan mengenai konsep etis dan tanggung jawab sosial yang seringkali diindahkan oleh banyak perusahaan mulai menarik perhatian publik terkait dengan kegiatan mencari keuntungan ekonomi dan kekuatan sosial yang dilakukan oleh perusahaan. Bahkan kemudian kita menyaksikan beberapa perusahaan terkenal di dunia seperti Nike dan Shell mengalami kerugian besar akibat kehilangan kepercayaan publik terkait dengan meluasnya pemberitaan mengenai perilaku tidak terpuji terkait operasional pabrik-pabrik mereka yang berada di negara-negara berkembang yang ternyata berkontribusi signifikan terhadap kerusakan lingkungan dan timbulnya masalah sosial. Kebangkrutan perusahaan besar lainnya seperti Enron dan Worldcom yang juga mempengaruhi ribuan pekerja dan investasi ekonomi kemudian menimbulkan banyak pertanyaan mengenai praktek kerja dan kredibilitas perusahaan yang ternyata bisa mengguncang kepercayaan publik yang berimplikasi terhadap keberadaan perusahaan.

Kondisi tersebut menjadi pengingat bagi para praktisi bisnis kemudian bahwa penekanan operaisonal perusahaan pada kepentingan ekonomi semata hanya akan merugikan bukan hanya reputasi organisasi tetapi juga kelangsungan hidup organisasi. Selain itu bencana tsunami akibat gempat bumi yang terjadi di Asia Selatan yang menimbulkan kerusakan yang tidak pernah terjadi sebelumnya dalam sejarah kemanusiaan membangkitkan perhatian dan tanggapan para pelaku bisnis, LSM dan 
pemerintah. Sehingga kemudian esensi dari kegiataan tanggung jawab sosial perusahaan (CSR) bergeser kearah pentingnya bagi perusahaan untuk melampaui kewajiban ekonomi dan hukumnya semata, serta bertindak dengan penuh tanggung jawab terhadap bagi keuntungan berbagai stakeholder-nya termasuk didalamnya adalah masyarakat secara luas.Di era milenium baru ini, kegagalan dalam melakukan hal tersebut ternyata dapat mengancam legitimasi organisasi tersebut dalam kegiatan operasionalnya. Pencarian tanpa henti untuk menyeimbangkan antara kepentingan stakeholders dan profit finansial, dipicu dengan meningkatnya ekspektasi publik tentang kewajiban sosial perusahaan yang akhirnya membuka jalan bagi berkembangnya gerakan CSR secara global.

Indonesia sendiri merupakan wilayah kajian yang menarik terkait dengan topik CSR.Hal ini dikarenakan Indonesia merupakan negara salah satu dari sedikit sekali negara di dunia yang berani mengintegrasikan nilai-nilai CSR kedalam perundang-undangan negara baik itu secara eksplisit maupun implisit.Kewajiban eksplisit mengenai CSR ditegaskan keberadaannya didalam UU Badan Usaha Milik Negara No. 19/2003, diikuti oleh UU Penanaman Modal No. 25/2007, serta UU Perseroan Terbatas No. 40/2007. Selain itu kewajiban mengenai CSR juga dapat ditemukan secara implisit dalam UU No. 41/1999 tentang Kehutanan, UU No. 22 Tahun 2001 tentang Minyak dan Gas Bumi, UU No. 7 Tahun 2004 tentang Sumber Daya Air, UU No. 4 Tahun 2009 tentang Pertambangan Mineral dan Batubara, serta UU No. 32 Tahun 2009 tentang Lingkungan.

Perdebatan sengit tentang hukum nasional dan internasional mengenai CSR dalam konteks Indonesia terus berkembang mengenai dikotomi mandatory-voluntary (kewajiban-sukarela), penciptaan beragam bentuk (semi-legal) instrumen CSR, serta cara untuk memverifikasi kepatuhan atau reaksi terhadap pelanggaran yang terjadi (Lambooy dkk, 2013). Pada saat yang sama, realitas di Indonesia menunjukan sejumlah tantangan yang luar biasa terhadap implementasi CSR pada tataran praktek, terutama dalam aktivitas ekonomi yang merupakan hal vital di Indonesia, seperti kehutanan dan pertambangan. Hal ini pernah dibawa ke hadapan Mahkamah Konstitusi Indonesia oleh sekelompok pebisnis Indonesia.Mereka menentang secara konstitusional kewajiban CSR yang dikenakan pada perusahaan oleh perundang-undangan Indonesia. Mereka menegaskan bahwa kewajiban hukum CSR melanggar prinsip-prinsip ekonomi berkaitan dengan efisiensi dan keadilan yang dijamin dalam pasal 33 (4) UUD 1945. Namun MK dalam keputusannya No. 53/PUU-VI/2008 menegaskan bahwa UU kewajiban CSR sesuai dengan UUD 1945, sebagaimana hukum ditetapkan oleh negara dalam kapasitas konsitusionalnya untuk mengontrol, mengelola, dan melindungi tanah, air, dan sumber daya alam Indonesia (pasal 33 (3) UUD 1945. MK juga menyatakan bahwa kewajiban CSR merepresentasikan nilai yang berkeadilan sosial yang merupakan salah satu dasar negara Republik Indonesia.

\section{DEFINISI DAN TERMINOLOGI CORPORATE SOCIAL RESPONSIBILITY}

Masalah fundamental dalam kajian CSR adalah bahwa tidak adanya definisi yang diterima secara universal mengenai konsep terebut. Bowen memberikan salah satu definisi awal tentang CSR sebagai sebuah kewajiban bagi para pelaku bisnis untuk melaksanakan kebijakan tersebut, untuk membuat keputusan dan atau mengikuti alur 
kebijakan yang diinginkan terkait tujuan dan nilai-nilai yang ada dalam masyarakat (Sriramesh dkk, 2007). Sejak saat itu kemudian, kajian ini terus berkembang dalam berbagai nama seperti misalnya tanggap sosial perusahaan (corporate social responsiveness) pada tahun 1970an dan kinerja sosial perusahaan (corporate social performance) pada tahun 1980an. Evolusi ini juga mencerminkan meningkatnya kesadaran pada tindakan dan performa penting organisasi yang pada awal mulanya seringkali diabaikan (Carroll, 1991).

Bowd, Harris dan Cornelissen (dalam May, Cheney \& Roper, 2007, hal. 121-131) mendefinisikan konsep CSR sebagai aktivitas dimana perusahaan vertanggung jawab baik itu secara eksplisit maupun tersirat oleh kontrak sosial dengan para stakeholders-nya untuk mematuhi hukum dan kewajiban pemerintah dan melaksanakannya sesuai dengan perilaku etis yang melampaui kewajiban hukum yang berlaku. Guna menekankan keabstrakan konsep 'perilaku etis'seperti yang disebutkan ini, Bowd dkk memberikan contoh mengenai perilaku etis tersebut seperti keterlibat proaktif komunitas, filantrofi, tata kelola pemerintahan, dan komitmen terhadap lingkungan.Definisi ini juga kemudian memerlukan komitmen pelakunya terhadap keberadaan akuntabilitas dimana perusahaan diwajibkan untuk mengukut dan mengaudit strategi, tujuan, prinsip, dan manifestasi kegiatan CSR-nya sekaligus terus memfokuskan diri untuk menghasilkan keuntungan bagi para investornya.

Pendapat yang menyatakan bahwa perusahaan memiliki kewajiban terhadap masyarakat berkembang saat bisnis sedang menikmati kondisi dimana perusahaan memiliki kekuasaan yang belum pernah terjadi sebelumnya (terutama terhadap masyarakat) namun hanya melaksanakan sedikit sekali tanggung jawab sosial (Wood, 1991; Carroll, 1999). Model CSR yang diajukan oleh Carrol yang menonjol selama tahun 1970an membingkai tanggung jawab bisnis kedalam empat komponen, yakni: ekonomi, hukum, etika, dan kebijaksanaan. Ketika penulis merefomurlasikan model tersebut pada tahun 1991, ia menggambarkannya dalam bentuk piramida dimana kinerja ekonomi merupakan fungsi yang paling mendasar (digambarkan di bagian bawah piramida) dan bergerak ke komponen hukum, etika, dan filantrofi.

$$
\text { Piramida CSR Carroll }
$$

menyatakan bahwa perusahaan yang bertanggung jawab secara sosial seharusnya mampu secara simultan menghasilkan keuntungan, mematuhi hukum, bersifat etis, dan menjadi corporate citizenship yang baik. Carroll juga secara spesifik membedakan antara tanggungjawab filantrofi dan sosial dimana pada kenyataannya banyak perusahaan berasumsi bahwa mereka telah bertanggung jawab secara sosial dengan menjadi warga perusahaan yang baik dalam komunitas.Namun menariknya, beberapa ahli dan para ekonom pada kenyataannya menolak filantrofi sebagai tindakan korporat yang bersifat legitimasi (Lantos, 2001; Friedman, 1970).Carrol sendiri menyatakan bahwa filantrofi meskipun sebenarnya sangat dibutuhkan, namun sebenarnya tidak begitu penting dibandingkan dengan ketiga komponen CSR lainnya. Sehingga perlu ditekankan bahwa meskipun keempat komponen yang ada tersebut dikonstruksikan terpisah namun pada dasarnya satu sama lain tidak bersifat ekslusif.

Berdasarkan pada kerangka berpikir Carroll tersebut Lantos kemudian mengklasifikasikan CSR kedalam tiga bentuk: etis, altruistis, dan strategis (2001). CSR etis 
merupakan bentuk minimal pemenuhan kewajiban ekonomi, hukum dan tanggung jawab etis perusahaan terhadap publiknya. CSR strategis dimaknai sebagai bentuk partisipasi perusahaan dalam kegiatan filantrofi yang pada dasarnya hanya akan menguntungkan perusahaan secara finansial dengan cara menarik publisitas positif dan mempertunjukan goodwill yang mereka milikiki. Sedangkan CSR yang bersifat altruistik merupakan tindakan filantrofi yang berkontribusi pada biaya yang dikeluarkan untuk para pemegang saham.Lantos menegaskan bahwa CSR yang bersifat altruistik tidak memiliki legitimasi. Meskipun memiliki orientasi yang berbeda, para ahli tersebut menegaskan adanya gagasan yang sama bahwa perusahaan tidak dapat beroperasi tanpa berinteraksi dengan masyarakat di mana mereka berada. Hubungan simbiosis ini disimpulkan Wood sebagai 'business and society are interwoven rather than distinct entities '(1991, hal. 695).

\section{BEBERAPA PENDEKATAN TERHADAP CSR}

Bertentangan degan para pendukung pendekatan bisnis dan masyarakat, para ekonom klasik memisahkan fungsi sosial dari fungsi ekonomi untuk menegaskan bahwa bisnis memiliki tanggung jawab utama yakni memaksimalkan keuntungan bagi pemilik atau para stakeholder-nya.Adam Smith (1863 sebagaimana dikutip oleh Lantos, 2001) yang merupakan pemikir pertama tentang pendekatan maksimalisasi nilai pasar mengemukakan bahwa dengan mengejar keuntungan perusahaan menghasilkan kebaikan sosial terbesar karena perpanjangan kapitalis tersebut tentunya membantu menyelesaikan masalah-masalah sosial masyarakat. Lantos (2001) menggunakan istilah CSR Ekonomi untuk mengacu pada aktivitas CSR yang berorientasi profit yang membebaskan perusahaan dari kontribusi sosial dikarenakan mereka telah membayar pajak dan gaji kepada para pegawainya dan bukannya memperbudak mereka (Phillips, 2003, hal. 18). Beberapa ekonom sejauh ini menyatakan bahwa satu-satunya tanggung jawab sosial perusahaan adalah mematuhi hukum yang berlaku.

Sama seperti pernyataan sebelumnya, ekonom penerima nobel Milton Friedman menawarkan pandangan dominan dan yang umum diterima yang merepresentasikan perbedaan fungsi sosial dari fungsi bisnis dengan menekankan bahwa 'business of business is business'(Klonoski, 2001). Namun demikian Friedman (1970) menyadari spektrum tanggung jawab moral dan etis yang dimiliki bisnis dengan memposisikan bahwa tanggung jawab sosial perusahaan adalah dengan menghasilkan uang sebanyakbanyaknya sambil memenuhi aturan dasar masyarakat baik itu yang tercantum di dalam hukum maupun yang terkandung dalam tradisi etis masyarakat.

Pendekatan ekonomi pada dasarnya mengabaikan fakta bahwa dalam upayanya untuk memaksimalkan keuntungan, keberadaan perusahaan pastilah mempengaruhi berbagai level stakeholders (Freeman \& McVea, 2001). Sedangkan pendekatan stakeholder terhadap CSR melihat perusahaan sebagai ' $a$ set of interrelated, explicit or implicit connections between individuals and or groups of individuals' (Lawton, Doh \& Rajwani, 2013, hal. 149) termasuk didalamnya siapa pun yang dapat mempengaruhi ataupun dipengaruhi oleh pencapaian tujuan-tujuan organisasi (Freeman \& McVea, 2001). Pendekatan ini membedakan antara stakeholder primer (mis. pegawai, konsumen dan pemasok) dan stakeholder sekunder (mis. media dan LSM). 
Pendukung pendekatan ini menyatakan bahwa perusahaan bertanggung jawab menangani kepentingan berbagai stakeholder (bukan hanya para pemilik dan/atau penanam saham) karena publik tersebut juga merupakan investor non-moneter yang dapat mempengaruhi pencapaian tujuan-tujuan perusahaan (May, Cheney \& Roper, 2007, hal. 122).

Akhirnya pendekatan kemasyarakatan (societal approach) memandang bahwa kewajiban perusahaan terhadap masyarakat secara keseluruhan, dimana perusahaan merupakan bagian terintegrasi didalamnya (van Marrewijk, 2003).Pendekatan ini menegaskan bahwa perusahaan beroperasi karena persetujuan publik (diberikan ijin untuk beroperasi) dengan tujuan untuk melayani secara konstruktif kebutuhan masyarakat, demi kepuasan masyarakat (van Marrewijk, 2003).Pendekatan ini menyarakankan pentingnya bagi perusahaan untuk mempertimbangkan posisi dan tindakan mereka dalam konteks kompleksitas kemasyarakatan dimana mereka menjadi bagian daripadanya.

Pendekatan

kemasyarakatan merupakan jawaban terhadap tantangan perusahaan dalam konteks kemasyarakatan yang kompleks di masa sekarang ini.perusahaan menghadapi tekanan yang semakin meningkat untuk mengatasi dan menjawab masalah-masalah sosial yang muncul akibat dari aktivitas perusahaan mereka (Pinkston \& Carroll dalam Yudarwati, 2011). Tuntuntan yang terus menerus dari berbagai kelompok, seperti misalnya lembaga swadaya masyarakat/LSM, konsumen bisnis, investor yang memiliki rasa tanggung jawab sosial, serikat buruh, serta komunitas (Doh \& Guay, 2006) memaksa perusahaan untuk mengalokasikan sumberdayanya untuk melaksanakan program CSR.
Harapan masyarakat terhadap perusahaan telah berkembang dalam merespon berbagai kesulitan yang mereka alami.Isu-isu sosial yang diarahkan kepada organisasi oleh para pemangku kepentingannya seringkali bervariasi dan tak pelak menimbulkan konflik (Maon, Lindgreen \& Swaen, 2008).Dalam situasi tersebut, maka perusahaan seringkali mengalami kesulitan dalam usahanya untuk mengidentifikasi masalah untuk pelaksanaan program CSR mereka.

\section{IMPLEMENTASI CSR DAN GERAKAN SOSIAL GLOBAL}

Kritik yang selama ini muncul terhadap konseptualisasi fungsional CSR adalah bahwa konsep ini bersifat terlalu inklusif dan 'terlalu abstrak kegunaannya'(Kristoffersen, Gerrans \& Clark-Murphy, 2005).Rowe dan Schlacter (dalam Abdul Hamid \& Atan, 2011) menyatakan bahwa ketidakjelasan istilah ini kemudian menjadi tameng bagi perusahaan yang sebenarnya enggan mengintegrasikan program CSR dalam operasionalnya.Kesulitan dalam mengukur manifestasi dan efek dari kegiatan CSR telah membuktikan faktor lainnya yang menghambat para manajer untuk merangkul konsep ini. Data yang bisa membuktikan asumsi keterkaitan antara CSR dan pencapaian tujuan-tujuan perusahaan (mis. profitabilitas, keberlangsungan, reputasi atau branding) merupakan argumentais yang paling baik dan paling efektik untuk mendorong pelaksanaan CSR (Commission of the European Communities, 2002).

Dalam beberapa tahun terakhir telah berkembang fakta di kalangan akademis yang menyatakan bahwa terdapat hubungan positif antara praktek CSR dengan kinerja finansial (Bodwell, Graves \& Waddock, 2002). Sampai saat ini belum ada model yang diterima secara 
umum mengenai audit praktek CSR meskipun Global Reporting Initiative (GRI) dan the International Organisation for Standardisation (ISO) telah melakukan upaya yang signifikan untuk memberikan panduan untuk tanggung jawab sosial. Namun demikian hal tersebut bukanlah sebuah pendekatan yang bersifat menyeluruh untuk mengaudit CSR sehingga kemudian banya perusahaan mengontrak lembaga audit untuk melakukan verifikasi tradisional, atau menggunakan konsultan ahli, atau bahkan menggunakan proses yang sudah dikustomisasi untuk mengukur aktivitas CSR mereka.

Disisi lain, meskipun konsep CSR sendiri berasal dari sistem liberal demokrasi di negara-negara Barat namun gerakan CSR telah berkembang menjadi sebuah gerakan global yang melibatkan berbagai sektor seperti bisnis, pemerintah, LSM, bahkan publik secara luas. Meningkatnya perhatian yang diberikan terhadap aktivitas CSR di ruang publik dan perusahaan seiring dengan proliferasi kajian akademik dan manajemen subyek tersebut (May, Cheeney \& Roper, 2007). Sebuah studi yang dilakukan oleh Echo Research (2003) menemukan bahwa liputan media mengenai masalah CSR telah meningkat secara dramatis sebanyak 407\% pada kurun waktu tahun 2000an di wilayah barat.

Di masa sekarang ini, CSR telah berkembang di seluruh dunia dan telah menjadi masalah yang penting dalam agenda diplomatik internasional.Beberapa kesepakatan antar pemerintah, seperti misalnya konvensi ILO telah ditetapkan selama bertahun-tahun terakhir ini. Pada pertemuan KTT Ekonomi Dunia di Davos pada tahun 2000 lalu, Sekretaris Jenderal PBB Kofi Annan meluncurkan Global Compact sebagai salah satu upaya untuk merangkul perusahaan di seluruh dunia agar secara sukarela mengintegrasikan praktek CSR kedalam operasional mereka. Sepuluh prinsip dasar yang meliputi empat area kunci yakni; hak asasi manusia, standar buruh, perlindungan lingkungan, dan anti korupsi telah ditetapkan di perusahaan diminta secara sukarela untuk mengadopsi prinsip-prinsip tersebut dan mengaturnya sendiri dalam kebijakan-kebijakannya. Selain itu pada konferensi internasional ISO tentang tanggung jawab sosial (2004) yang dihadiri oleh para stakeholder dari 66 negara pada tahun 2004 lalu menghasilkan konsensus di antara para peserta untuk mendukung kerja ISO tentang CSR yang menegaskan tanggung jawab sosial merupakan hal yang penting secara global sehingga perlu dilakukan secara jelas di seluruh dunia.

Globalisasi memainkan peran yang signifikan sebagai katalis gerakan CSR.Hal ini tidaklah mengherankan dimana perusahaan multinasional (MNC) merupakan pendukung utama gerakan CSR mengingat ada banyak hal yang dipertaruhkan bagi keberlangsungan perusahaan mereka (Commission of the European Communities, 2001). Hal ini dikarenakan sebagian besar perusahaan multinasional tersebut berkantor pusat di negara-negara demokrasi liberal di wilayah barat dimana kemudian mereka seringkali ditekan oleh regulasi pemerintah, media massa, dan kelompok swadaya masyarakat (LSM) agar menjalankan tanggung jawab sosialnya. MNC tersebut tersebar di seluruh dunia dengan jaringan pasokan dan pabrikpabrik manufaktur yang berlokasi di sejumlah negara.Selain itu, operasional perusahaan dituntut menjadi lebih transparan seiring dengan meningkatnya teknologi informasi dan komunikasi.Meningkatnya keperluan akan visibilitas ini adalah untuk memastikan bahwa tindakan perusahaan yang bersifat tidak etis 
atau tidak bertanggung jawab akan semakin rentan dari pengawasan dan kritisisme publik. Seperti misalnya perusahaan Nike yang harus berjuang keras untuk meraih kembali reputasinya bertahun-tahun setelah skandal tenaga kerjanya seiring dengan upaya peningkatkan kondisi kerja yang lebih baik (Knight \& Greenberg, 2002). Sebuah studi tentang Sosial dan Lingkungan pada tahun 2001 sempat menempatkan Nike pada tingkat teratas perusahaan yang gagal memenuhi tanggung jawab sosialnya pada saat itu.

\section{CSR DI ASIA DAN INDONESIA}

Kesadaran mengenai dan pengadopsian praktek CSR sendiri masih cenderung rendah di Asia jika dibandingkan dengan negara-negara maju di benua Barat.Globalisasi nampaknya muncul sebagai unsur utama terbesar yang mendorong gerakan CSR di Asia (Idowu \& Filho, 2009, hal. 28).Perusahaan-perusahaan yang berbasis di Asia yang tergabung dalam pasar internasional meningkatkan standar program CSR mereka untuk mengukur ekspektasi para stakeholder global mereka agar tetap bisa bertahan dalam kompetisi dunia (Khanna, Palepu \& Srinivasan, 2004).Bagaimana CSR dipersepsikan dan di praktekkan dibentuk oleh budaya, agama, politik, dan juga kondisi sosial ekonomi. Sehingga nampaknya terdapat perbedaan yang signifikan tentang cara bagaimana CSR diimplementasikan di berbagai negara dan wilayah yang berbeda (Bronn \& Vrioni, 2001).

Kekuatan penggerak program CSR di Indonesia juga berasal dari gerakan global internasional yang mengacu pada konsep etika bisnis. Konsep tersebut pada awalnya dimulai oleh perusahaan asing yang beroperasi di wilayah Indonesia (termasuk didalamnya Badan Usaha Milik Negara/BUMN) meskipun kebanyakan mereka masih melakukan aktivitas yang terbatas pada program charity atau amal. MNC yang beroperasi di Indoensia mencoba mengadopsi keijakan CSR yang diawali oleh perusahaan induk mereka terutama setelah laporan kasus yang menimpa pabrik manufaktur Nike tahun 1992 terkait masalah buruh dan HAM.

Meningkatnya inisiatif pelaksanaan CSR telah memunculkan salah satunya pembentukan Komite Nasional Tatakelola Korporasi yang bekerja untuk membangun Kode Etik bagi pelaksanaan Good Corporate Governance dan beberapa forum korporasi CSR yang dipicu oleh berbagai masalah sosial dan bencana alam yang terjadi. Dikarenakan panduan nasional tentang pemberdayaan masyarakat cenderung berbasis sektoral maka kebanyakan MNC mengadopsi panduan yang ada secara internasional. Salah satunya adalah pembentukan organisasi non-profit bernama Indonesia Business LInks (IBL) pada tahun 1998 yang merupakan inisatif para pemimpin bisnis terkemuka di Indoensia untuk mempromosikan atau mengadvokasi semangat good corporate citizenship diantara antara perusahaan dan membangun kemitraan untuk pembangunan.

Selain itu, kecelakaan yang terjadi seperti pada kasus Buyat (Newmont Minahasa), kasus Papua (Freeport) atau yang paling mutakhir adalah kasus lumpur panas di Sidoarjo (Lapindo Brantas) membuka mata para pemimpin bisnis dan masyarakat luas mengenai pentingnya kegiatan CSR. Selama konferensi nasional mengenasi CSR yang diselenggarakan oleh IBL pada tahun 2006 lalu, para peserta menegaskan bahwa CSR menjadi semakin penting keberadaannya bagi perusahaan di masa mendatang. Sehingga kemudian terdapat indikasi kuat terjadinya peningkatan aktivitas CSR sejak tahun 2006 terkait masalah etika bisnis dan corporate governance (Lindgren, 2006). 
Meskipun Indonesia menjadi negara tertinggi di ASEAN dalam hal pembuatan laporan berkelanjutan (sustainability reports ) mengenai CSR yang dilakukan oleh perusahaan, namun ternyata secara kuantitas hanya terdapat 40 perusahaan yang melaporkan kegiatan CSR mereka tersebut (SWA, 2013). Dari total keseluruhan itu pun hanya sekitar 29 yang laporannya mengacu pada standar pelaporan yang ditentukan oleh Global Reporting Initiative (GRI), sedangkan sisanya hanya sekedar laporan berupa satu atau dua halaman laporan biasa. Hal terpenting lainnya menurut Chambers $\mathrm{dkk}$ (Yudarwati, 2011) adalah ternyata Indonesia memiliki keterlibatan masyarakat yang paling rendah dalam upaya perencanaan dan pengimplementasian CSR dibandingkan negara-negara lain di ASEAN.

CSR di Indonesia sendiri diimplementasikan dalam berbagai bentuk aktivitas yang dikenal dengan berbagai nama dan bentuk. Misalnya dengan istilah pemberdayaan masyarakat (community empowerment), program kemitraan, Program Kemitraan Bina LIngkungan (PKBL) yang diinisiasi oleh pemerintah dan menarget Badan Usaha Milik Negara (BUMN) (Oktavia \& Meaton, 2014).Program-program tersebut umumnya ditujukan untuk memberikan kontribusi positif bagi masyarakat, khususnya masyarakat yang ada di sekitar perusahaan. Namun sayangnya implementasi program yang dilaksanakan oleh perusahaanperusahaan tersebut masih sangat sedikit jika dibandingkan dengan keuntungan yang didapatkan oleh perusahaan, jumlah perusahaan yang beroperasi di Indonesia dan jumlah kegiatan yang seharusnya dapat dilakukan mengingat tingginya masalah sosial dan lingkungan yang dihasilkan oleh perusahaan-perusahaan tersebut, seperti penggundulan hutan, polusi, dan kerusakan yang diterima oleh masyarakat adat (WALHI, 2006). Berbagai gerakan organisasi sosial kemudian hadir secara masif menandai meningkatnya kepedulian masyarakat terhadap perkembangan CSR di Indoensia agar mampu melakukan signifikansi hubungan antara masyarakat, bisnis, dan pemerintah; seperti misalnya Business Watch Indonesia (BWI), CSR Indonesia, Lingkar Studi CSR dan Public Interest Advocacy Center (PIRAC). Namun demikian pelaksanaan CSR masih saja berdasar pada inisiatif perusahaan yang cenderung berbasis sektoral (Waagstein, 2011).

\section{CORPORATE}

SOCIAL

\section{RESPONSIBILITY DAN PUBLIC} RELATIONS

Terkait dengan rendahnya baik itu kuantitas maupun kualitas pelaksanaan CSR maka kekosongan inilah yang kemudian menjadi salah satu bagian dari tanggungjawab para praktisi PR yang harus disikapi dan disiasati dengan baik sesuai dengan peran dan fungsi profesionalnya. Konsep tanggung jawab sosial atau social responbility berkembang dalam ranah keilmuan etika bisnis sejak tahun 1950an, yang kemudian didefinisikan sebagai moralitas dalam praktek perusahaan yang berkembang pada tahun 1980an dan 1990an yang kemudian mengarah pada konsep Corporate Social Responsibility di era modern ini (Carroll, 1999). Di masa awal-awal penerapan paradigma CSR, unsur komunikasi bukanlah hal yang dipertimbangkan dalam kaitannya dengan manajemen pencitraan dan program kerja Public Relations. Perusahaan pada mulanya menerapkan CSR hanya dikarenakan tekanan yang mereka terima dari publik eksternal, seperti yang diajukan oleh para aktivis konsumeris, para environmentalis, dan aktivis sosial (Shah \& Chen, 2010). Hal inilah yang 
kemudian harus dievaluasi kembali dimana menurut Pinskton \& Carrol (dalam Shah \& Chen, 2010.) perusahaan haruslah mengembalikan rasionalisasi moralitas mereka pada praktek-praktek yang bersifat etis, sehingga harus memastikan bahwa CSR yang mereka lakukan sesuai dengan tuntutan yang dibuat oleh para praktisi PR yang merupakan ethical guardian dalam organisasi (Corbett, 2012). Frankental (2001) menegaskan bahwa CSR merupakan 'the invention of public relations', dimana perusahaan bekerja dalam dunia yang sangat kompleks dengan berbagai perbedaan budaya yang merupakan realitas sosial dominan manusia. Sehingga perusahaan seharusnya melaksanakan fungsi CSR mereka sebagaimana layaknya PR dikarenakan keduanya merupakan simbiosis realitas sosial dan dianggap sama satu sama lain.

Beberapa penelitian menemukan beberapa hal yang menyatakan kesamaan antara Public Relations dan CSR (Juholin, 2004; Goodwin \& Bartlett, 2008; Shah \& Chen, 2010; Vallentin, 2004; Frankental, 2001). Jika menengok pada asal muasalnya, kajian PR dan CSR sama-sama dikembangkan dari pendekatan manajemen/sosial-ekonomi dan kemudian etika-sosial dimana perbedaan ditemukan hanya pada unsur komunikasi yang digunakan. Model PR simetris dua arah (twoway symmetrical model) yang dikemukakan oleh Grunig, Grunig \& Ehling (Shah \& Chen, 2010) menjelaskan dengan lebih baik kesamaan antara program dan proses CSR meskipun jika mengikuti model ini perusahaan dan publik sama-sama dapat mengubah sikap mereka dengan aliran komunikasi yang lebih baik dalam dinamika sosial kultural dan dapat berperilaku lebih efisien, lebih etis dan bertanggung jawab terhadap masyarakat. Model PR yang dikemukakan oleh Cutlip, Center \& Broom
(2005) dan juga oleh Clarkson (dalam Zu, 2009, hal. 28 \& 41) tentang CSR mengidentifikasi adanya beberapa kesamaan. Kedua model tersebut sama-sama mengidentifikasi adanya model yang sama, namun PR dimulai dengan prospek masalah sedangkan proses CSR dimulai dengan kesadaran akan sebuah masalah. Sedangkan tahapan kedua, yakni perencanaan yang merupakan proses inti baik itu PR dan CSR dimana pemprograman dan analisa memiliki perbedaan. Di tahapan ketiga, PR berkaitan dengan pengambilan tindakan dalam konteks eksekusi proses komunikasi, tindakan CSRberkaitan dengan pengembangan kebijakan. Akhirnya, di langkah keempat, keseluruhan program PR dievaluasi sedangkan kalau dalam model CSR dilakukan eksekusi terkait dengan kebijakan yang ditetapkan oleh perusahaan.

Model Cutlip, Center \& Broom (2005) danClarkson (dalam Zu, 2009) membahas mengenai kepentingan para stakeholder, dimana masyarakat bukanlah tema fokus model ini. Namun demikian model ini memberikan kerangka dasar mengenai penelahaan lebih lanjtu dan menawarkan proses yang lebih mudah. Dalam rangka menemukan kesamaan antara PR dan CSR, Clark (dalam Goodwin \& Barlett, 2008) menawarkan model untuk memahami proses PR dan CSR berdasarkan pada kajian pustaka yang ada seperti dibawah ini.

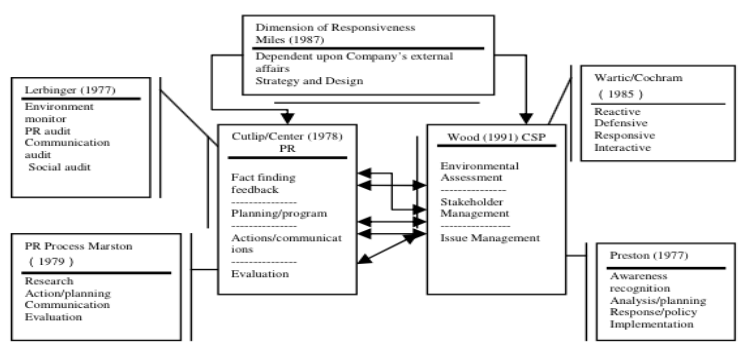

Gambar 1: Kesamaan antara PR dan CSR Sumber: Clarkson, 1995 
Clark meliat bahwa manajemen PR Cutlip dan Center dan model kinerja sosial perusahaan Wood ternyata memiliki kesamaan. Model Lerbinger memberikan posisi analisis terhadap program manajemen PR yang menawarkan bahwa sebuah hubungan tidak bisa terjadi tanpa adanya keterlibatan lingkungan dan secara komprehensif haruslah melibatkan 'pengawasan lingkungan, PR, komunikasi dan audit sosial'yang mengacu pada hubungan yang baik. Konsep 'audit'sendiri mengarah pada semua proses komunikasi simetris dalam program PR dimana perusahaan haruslah bertanggung jawab terhadap semua tindakan dan perilakunya terhadap para stakeholders. Sedangkan dalam model CSP-nya Wood, konsep 'environement' atau lingkungan merupakan topik sentral bagi keseluruhan program Kinerja Sosial Perusahaan (Corporate Social Performance). Lingkungan sendiri dapat didefinisikan sebagai koherensi antara entitas sosial, politik, ekonomi dan budaya didalam sebuah sistem.Selain itu, model Wartic dan Cochran mengidentifikasi pentingnya respon terhadap lingkungan melalui perilaku reaktif, defensif, responsif dan juga interaktif perusahaan. Disisi lain, dimensi responsif Miles menghubungkan antara PR dan CSP melalui hubungan eksternal perusahaan dengan strategi dan desain hubungan eksternya yang mempengaruhi intensitas hubungan yang terjadi. Kemudian, model Cutlip dan Wood mengenai proses 'Lingkungan'dan 'Komunikasi'merupakan faktor dominan dalam keseluruhan proses. Model PR Marston dan CSP Preston menempatkan manajemen strategis sebagai unsur penting dari fenomena keseluruhan. Sehingga secara keseluruhan dapat dikatakan bahwa PR sebagai bentuk dari Kinerja Sosial Perusahaan (CSP) atau Tanggungjawab Sosial Perusahaan (CSR) berkisar dalam konteks hubungan dengan lingkungan dan bersifat komprehensif atau juga merupakan bagian dari proses PR yang baik yang berdasarkan pada strategi internal terbaik yang terhubung dengan realita sosial di eksternal.

Salah satu pendekatan yang dapat digunakan untuk memahami fungsi PR dalam masalah CSR adalah melalui peran organisasional praktisi PR. Seperti yang dinyatakan oleh Dozier (dalam Holstrom, 1997), bahwa peranan praktisi PR merupakan kunci untuk memahami fungsi PR dan komunikasi organisasional.Peran praktisi berada di nexus jaringan konsep-konsep yang mempengaruhi pencapaian professional praktisi, struktur dan process dari fungsi yang ada dalam organisasi, serta kapasitas organisasi untuk mendominasi atau bekerjasama dengan lingkungan mereka.

Berdasarkan atas konsep PR yang merupakan bagian dari fungsi manajemen, maka Cutlip (dalam Theaker dan Yaxley, 2013) menyatakan bahwa PR merupakan bagian dari fungsi manajemen yang unik yang membantu membangun dan mempertahankan alur komunikasi, pemahaman, penerimaan dan kerjasama antara organisasi dan publiknya; melibatkan majemen masalah atau isu; membantu manajemen terus mendapatkan informasi dan bersikap responsif terhadap opini publik; mendefinisikan dan menegaskan tanggung jawab manajemen untuk melayani kepentingan publik; membantu manajemen mengatasi dan secara efektif memaksimalkan perubahan sebagai sistem peringatan untuk mengatasi perubahan trend; serta menggunakan penelitian serta komunikasi yang baik dan beretika sebagai alat utama.

Pernyataan mengenai peran PR yang paling sering digunakan dicetuskan oleh Broom dan Smith yang menawarkan empat 
peran praktisi PR. Terdiri dari peranan majerial seperti penasehat ahli, fasilitator proses pemecahan masalah, fasilitator komunikasi, sampai ke peran teknisi komunikasi (Theaker, 2012). Sebagai seorang penasehat ahli (expert prescriber), praktisi PR menjadi orang yang dianggap ahli dalam organisasinya dan memberikan pertimbangan solusi terhadap masalah-masalah kehumasan bagi manajemen.Peran fasilitator komunikasi berarti bahwa praktisi PR memfasilitasi komunikasi antara organisasi dan publiknya.Peran ini mengarahkan praktisi PR untuk menjadi pendengar yang sensitive serta sebagai penampung informasi (Cutlip, 2011). Fasilitator proses pemecahan masalah mengacu pada konsep bahwa praktisi PR bekerjasama dengan manajemen untuk memecahkan masalah-masalah kehumasan. Disini para praktisi PR berpartisipasi dalam tim perencanaan strategis. Sebagai seorang teknisi, praktisi PR memproduksi materi informasi dan menjadi eksekutor dari kebijakan yang dibuat oleh manajemen. Dalam kaitannya dengan aktivitas CSR, Yudarwati (2011) menyatakan bahwa peran yang dilaksanakan oleh praktisi PR tergantung pada model komunikasi yang dilaksanakan oleh organisasi. Komunikasi simetris dua-arah memungkinkan para praktisi PR menjalankan peran manajerial.Namun jika pendekatan propaganda yang dijalankan maka kecenderungannya adalah PR sebagai pendukung teknis semata.

\section{KESIMPULAN}

Di masa sekarang ini penciptaan nilai mengenai triple bottom line (profit, people, and planet) dalam dunia bisnis merupakan hal yang fundamental dalam konsep CSR.Namun demikian, proses menngkatkan performa sosial korporat tidak diragukan lagi meliputi adanya perubahan sosial dan sosial yang lebih luas yang tidak mudah untuk diubah dalam waktu singkat.Masalah-masalah multidimensi yang terjadi dalam kehidupan sosial masyarakat mempengaruhi penerimaan organisasi terhadap keberadaan CSR dalam konteks Indonesia.

Meskipun ada beberapa perusahaan yang secara tulus mengupayakan implementasi praktek CSR yang baik, namun dugaan bahwa CSR hanya sekedar 'kosmetik'atau sekedar untuk mendapatkan legitimasi semata mempengaruhi opini publik tentang perusahaan. Perusahaan yang hanya mencari keuntungan semata, menjadikan sifat sukarela atas pelaksanaan CSR dan disertai dengan lemahnya penegakan hukum terhadap perilaku etis di Indonesia menjadi alasan untuk menghindari melakukan praktekpraktek CSR ini. Di sisi lain, perusahaan yang benar-benar berusaha menegakan keadilan sosial merasa bahwa kondisi sekarang ini sangatlah membingungkan. Beberapa hambatan yang menjadikan perusahaan tidak mampu mengimplementasikan CSR secara utuh seringkali berasal dari lingkungan eksternal dan juga sistem internal yang ada.Kurangnya pemahaman mengenai CSR merupakan hambatan utama dalam membangun pemahaman antara bisnis, pemerintah, dan masyarakat sipil.Sehingga perlu adanya upaya tertentu yang bisa menjembatani kesenjangan tersebut.

Akhirnya, keberadaan praktisi PR sangat tepat untuk menangani masalah tanggung jawab sosial (CSR) yang mengikat perusahaan dikarenakan mereka dilatih untuk melihat baik itu dari sudut pandang perusahaan maupun publik serta menyeimbangkan kepentingan perusahaan dengan kepentingan publik. Para ahli menegaskan bahwa dibandingkan pegawai lain di perusahaan, praktisi PR merupakan yang terbaik untuk membangun kesadaran 
korporasi, atau kesadaran sosial, atau kesadaran etis. Kesadaran seperti yang dinyatakan oleh Bok (dalam Bowen, 2005) 'is seen as another and more exacting sel'. Bowen (2005) menegaskan bahwa kesadaran merepresentasikan diri kita yang lebih baik atau sesuatu yang seharusnya dilakukan untuk menyelesaikan dilema yang berkaitan dengan panduan etika normatif. Kesadaran ini memberikan panduan mengenai apa yang terbaik untuk mengatasi dilema tersebut. Praktisi PR dianggap sebagai kesadaran korporat karena mereka menggabungkan masalah etika dan kepetingan publik yang beragam kedalam pengambilan keputusan organisasi.Sebagai kesadaran korporat, praktisi PR mendukung organisasi untuk mempertahankan hubungan antara organisasi dengan publik, dengan mengelola aliran informasi diantara mereka, mengartikulasikan kepentingan publik kepada organisasi dan memastikan pengimplementasian kebijakan adalah untuk keuntungan kedua belah pihak.

\section{DAFTAR PUSTAKA}

Abdul Hamid, F.Z. dan Atan, R. (2011), 'Corporate Social Responsibility by the Malaysian Telecommunication Firms, The Special Issue on Contemporary Issues in Business and Economics, Vol. 2, No. 5, hal. 198208.

Bowen, S.A. (2005), 'A Practical Model for Ethical Decision Making in Issues Management and Public Relations', Journal of Public Relations Research, Vol. 17, No. 3, hal. 191216.

Bronn, P.S. dan Vrioni, A.B. (2001), 'Corporate Social Responsibility and Cause-Related Marketing: An Overview', International Journal of
Advertising, Vol. 20, No. 2, hal. 207222.

Carroll, A.B. (1991), 'The Pyramid of Corporate Social Responsibility: Toward the Moral Management of Organisational Stakeholders', Business Horizons, Vol. 34, Iss. 4, July-August, hal. 39-48

Carroll, A.B. (1999), 'Corporate Social Responsibility: Evolution of a Definitional Construct', Business and Society', Vol. 38, No. 3, hal. 268295.

Clarkson, M.B. (1995), ‘A Stakeholder Framework for Analyzing and Evaluating Corporate Social Performance', The Academy of Management Review, Vol. 20, No. 1, hal.92-117.

Commission of the European Communities (2002), 'Corporate Social Responsibility: A Business Contribution to Sustainable Development', Communication From the Commission.

Commission of the European Communities (2001), 'Promoting a European Framework for Corporate Social Responsibility', Green Paper.

Corbett, G.F. (2012), 'All Public Relations Professionals Are Liars?-That is Not the Case in America', The Guardian, Vol. 9 Maret.

Cutlip, S.M., Center, A.H., dan Broom, G.M. (2005), Effective Public Relations, Edisi ke-9, Prentice Hall, New Jersey.

Doh, J.P. \& Guay, T.R. (2006), 'Corporate Social Responsibility, Public Policy, and NGO Activism in Europe and the United States: An InstitutionalStakeholder Perspective', Journl of 
Management Studies, Vol. 43, Iss. 1, hal.43-73.

Frankental, P. (2001), 'Corporate Social

Responsibility-a

PR

Invention?',Corporate

Communications: An International

Journal, Vol. 6, Iss. 1, hal.18-23.

Freeman, R.E., dan McVea, J. (2001), 'A

Stakeholder Approach to Strategic

Management', Darden Business

School Working Paper, No. 01-02.

Friedman, M. (1970) 'The Social Responsibility of Business is to Increase its Profits', The New York Times Magazine, Iss. 13 September.

Goodwin, F. dan Bartlett, J.L. (2008), 'Public

Relations and Corporate Social Responsibility (CSR), Public Relations and CSR Review Working Paper, QUT Digital Repository.

Holstrom, Susanne, (1997), 'Two Basically

Differing Roles for Public Relations In the Corporate Practice of Social Responsibility', Journal of Communication Management, hal 122.

Idowu, S.O. dan Filho, W.L. (2009), Global Practices of Corporate Social Responsibility, Springer, Berlin.

Juholin, E. (2004), 'For Business of the good of All? A Finish Approach to Corporate Social Responsibility', Corporate Governance: The International Journal of Business in Society', Vol. 4, Iss. 3, hal.20-31.

Khanna, T., Palepu, K.G., dan Srinivasan, S. (2004), 'Disclusure Practices of Foreign Companies Interacting with U.S. Markets', Journal of Accounting Research, Vol. 42, Iss. 2, hal.475508.
Klonoski, E. (1991), 'Foundational Considerations in the Corporate Social Responsibility Debate', Business Horizons, Vol. 34, No. 4, hal.9-18.

Knight G. dan Greenberg, J. (2002), 'Promotionalism and Subpolitics: Nike and Its Labor Critics', Management Communication Quarterly, Vol. 15, No. 4, hal. 541570.

Kristoffersen, I., Gerrans, P. dan ClarkMurphy, M. (2005), 'The Corporate Social Responsibility and the Theory of the Firm', FIMARC Working Paper Series 0505.

Lambooy, T.E., Kusumadara, A., Argyrou, A., dan Istiqomah, M. (2013), CSR In Indonesia Legislative Developments and Case Studies, Konstitusi Press, Jakarta.

Lantos, G.P. (2001), 'The Boundaries of Strategic Corporate Social Responsibility', Journal of Consumer Marketing, Vol. 18, Iss.7, hal.595632.

Lawton, T., Doh, J.P., dan Rajwani, T. (2013), Aligning for Advantage: Competitive Strategies for the Political and Social Arenas, Oxford University Pers, Oxford.

Lindgren, D. (2006), 'Corporate Social Responsibility Among Foreign Multinational Companies in Indonesia', Professional Research Paper, Ohio University.

Maon, F., Lindgreen, A., dan Swaen, V. (2008), 'Thinking of the Organisation as a System: The Role of Managerial Perceptions in Developing a Corporate Social Responsibility Strategic Agenda', 
Systems Research and Behavioural Science, vol. 25, Iss. 3, hal.413-426.

May, S., Cheney, G., dan Roper, J. (2007),

The Debate Over Corporate Social Responsibility, Oxford University Press, New York.

Oktavia, S. dan Meaton, J. (2014), 'Corporate Social Responsibility (CSR) Public Policy in Indonesia: Profile, State of the Art and the Key Motive', 4th International Conference on Management Proceeding, Bali, 16-17 Juni 2014.

Phillips, R. (2003), Stakeholder Theory and Organisational Ethics, BerrettKoehler Publishers Inc., San Fransisco.

Shah, M.H. dan Chen, X. (2010), 'Relational Corporate Social Responsibility: Public Relations Implications in Culturally Confucius China', International Journal of Business and Social Science, Vol. 1, No. 3, hal. 117-123.

Sriramesh, K., Hallahan, K., Holtzhausen, D., van Ruler, B., dan Vercic, D. (2007), 'Defining Strategic Communication', International Journal of Strategic Communication, Vol. 1, No. 1, hal. 3-35.

SWA (2013, 3 Januari), 'Perusahaan Pembuat Laporan Keberlanjutan Kian Banyak di Indonesia.

Theaker, A. (2012), The Public Relations Handbook, Edisi ke-4, Routledge, New York.

Theaker A. dan Yaxley, H. (2013), The Public Relations Strategic Toolkit, Routledge, New York.

Vallentin, S. (2004), 'Corporate Social Responsibility and Public Opinion', PR Working Papers, Copenhagen Business School. van Marrewijk, M. (2003), 'Concepts and Definitions of CSR and Corporate Sustainability: Between Agency and Communion', Journal of Business Ethics, Vol. 44, Iss. 2-3, hal.95-105.

Waagstein, P.R. (2011), 'The Mandatory Corporate Social Responsibility in Indonesia: Problems and Implications', Journal of Business Ethics, Vol. 98, Iss. 3, hal.455-466.

Wahana Lingkungan Hidup Indonesia (WALHI), (2006), Pelanggaran HAM dan Kejahatan Ekologis PT Lapindo Cederai Masyarakat Luas, Website Content.

Waddock, S.A., Bodwell, C., dan Graves, S.B. (2002), 'Responsibility: The New Business Imperative', The Academy of Management Executive, Vol. 16, No. 2, hal. 132-148

Wood, D.J. (1991), 'Corporate Social Performance Revisited', The Academy of Management Review, Vol. 16, No. 4, October, hal. 691718.

Yudarwati, G.A. (2011), The Enactment of Corporate Social Responsibility and Public Relations Practices: Case Studies from the Indonesian Mining Industry, Disertasi Doktor School of Media and Communication, RMIT University

Zu, L. (2009), Corporate Social Responsibility, Corporate Restructuring and Firm's Performance, Springer, Berlin. 